TITLE:

\title{
Ligand-based solid solution approach to stabilisation of sulphonic acid groups in porous coordination polymer $\mathrm{Zr}\left\{\{6\} \mathrm{O} \_\{4\}(\mathrm{OH}) \_\{4\}(\mathrm{BDC}) \_\{6\}(\mathrm{UiO}-\right.$ $66)$.
}

\section{$\operatorname{AUTHOR}(\mathrm{S}):$}

Foo, Maw Lin; Horike, Satoshi; Fukushima, Tomohiro; Hijikata, Yuh; Kubota, Yoshiki; Takata, Masaki; Kitagawa, Susumu

\section{CITATION:}

Foo, Maw Lin ... [et al]. Ligand-based solid solution approach to stabilisation of sulphonic acid groups in porous coordination polymer Zr__6\}O_ $\{4\}(\mathrm{OH}) \_\{4\}(\mathrm{BDC}) \_\{6\}(\mathrm{UiO}-66)$. Dalton transactions 2012, 41(45): 13791-13794

\section{ISSUE DATE:}

2012-07-17

\section{URL:}

http://hdl.handle.net/2433/176397

\section{RIGHT:}

(c) The Royal Society of Chemistry 2012.; この論文は出版社版でありま せん。引用の際には出版社版をご確認じ利用ください。; This is not the published version. Please cite only the published version. 


\title{
Transactions
}

\section{Ligand-based solid solution approach to stabilisation of sulphonic acid groups in porous coordination polymer $\mathrm{Zr}_{6} \mathrm{O}_{4}(\mathrm{OH})_{4}(\mathrm{BDC})_{6}(\mathrm{UiO}-66)$}

\author{
Maw Lin Foo, ${ }^{\text {a,d }}$ Satoshi Horike, ${ }^{\text {bcc }}$ Tomohiro Fukushima, ${ }^{b}$ Yuh Hijikata, ${ }^{b}$ Yoshiki Kubota, ${ }^{\mathrm{e}}$ Masaki \\ Takata $^{\mathrm{f}}$ and Susumu Kitagawa ${ }^{\text {a,b,d }}$
}

\author{
${ }_{5}$ Received (in $\left.X X X, X X X\right)$ Xth $X X X X X X X X X 20 X X$, Accepted Xth XXXXXXXXX 20XX \\ DOI: $10.1039 / b 000000 x$
}

By adopting a ligand-based solid solution approach, the sulphonic acid functional group can be successfully incorporated into a porous coordination polymer with $\mathrm{UiO}-66$ ${ }_{10}$ structure type. $\mathrm{Zr}_{6} \mathrm{O}_{4}(\mathrm{OH})_{4}\left(\mathrm{BDC}_{-} \mathrm{SO}_{3} \mathrm{H}\right)_{1.1}(\mathrm{BDC})_{4.9}$ possess enhanced heat of adsorption for carbon dioxide and acetone compared to $\mathrm{Zr}_{6} \mathrm{O}_{4}(\mathrm{OH})_{4}(\mathrm{BDC})_{6}$.

In the past decade, the field of metal organic frameworks (MOF) or porous coordination polymers (PCPs) ${ }^{1}$ has seen explosive 15 growth due to the modular nature of their synthesis, crystalline nature and porous structures. Possible applications of these materials are in gas separation/storage, catalysts, ion conductivity and drug delivery. ${ }^{2}$ However, for practical usage, PCPs should be thermally, hydrolytically and chemically stable. ${ }^{3}$ ${ }_{20} \mathrm{Zr}_{6} \mathrm{O}_{4}(\mathrm{OH})_{4}(\mathrm{BDC})_{6}$ or $\mathbf{1}$, is a recently reported compound that exhibits robust stability due to its strong $\mathrm{Zr}-\mathrm{O}$ bonds and 12coordinated 'Maltese Cross' Structural Building Unit (SBU). ${ }^{4}$ By utilizing 2-substituted 1,4-benzene carboxylic acids such as - $\mathrm{Br}$, $\mathrm{NH}_{2}$ and $-\mathrm{NO}_{2}$, various functionalised UiO-66 can be 25 successfully synthesized. ${ }^{5}$

The incorporation of sulphonic acid, $-\mathrm{SO}_{3} \mathrm{H}$ functional group into PCPs is potentially interesting due to the strong acidity of its acidic proton. This renders the resultant material useful for proton conductivity and catalysis, as best embodied by Nafion. ${ }^{6}$

${ }_{30}$ However, despite reports of PCPs with alkyl sulphonic acid groups using post-synthetic methods, ${ }^{7}$ reports of MOFs with aryl sulphonic acid groups has thus far been limited. Recently, $\mathrm{Cr}$ MIL-101 with aryl sulphonic acid functional groups has been reported using the sodium salt of 2-sulfonylterephtalic acid (2$35 \mathrm{NaSO}_{3}-\mathrm{H}_{2} \mathrm{BDC}$ ) as the starting material. ${ }^{8}$ The sodium ion was exchanged in-situ with $\mathrm{H}^{+}$by $\mathrm{HCl}$ in the reaction solvent. Another approach is to graft sulphonic acid groups via postsynthetic treatment. ${ }^{9}$

To achieve modulation of the physical properties of a target PCP 40 crystal structure in a designed fashion, one approach is to combine different ligands of the same denticity in different proportions while keeping the crystal structure invariant. This approach has been termed solid solution ${ }^{10}$ (from classical solid state chemistry), mixed $\mathrm{MOFs}^{11}$ (MIXMOF) or multivariate ${ }_{45} \mathrm{MOFs}^{12}$ By using this strategy, properties such as optimization of gas separation property, ${ }^{10,12}$ catalytic activity ${ }^{11}$ have been successfully modulated.

In this communication, we demonstrate the synthesis of an aryl substituted

sulphonic

acid,

$50\left[\mathrm{Zr}_{6} \mathrm{O}_{4}(\mathrm{OH})_{4}\left(\mathrm{HSO}_{3} \mathrm{BDC}\right)_{6}\right] \supset\left(\mathrm{CH}_{3} \mathrm{COOH}, \mathrm{DMF}, \mathrm{H}_{2} \mathrm{O}\right)$ or $2 \supset \mathrm{G}$ via in-situ ion exchange of $\mathrm{Na}^{+}$for $\mathrm{H}^{+}$of the $\mathrm{NaSO}_{3}-\mathrm{H}_{2} \mathrm{BDC}$ ligand in the acidified reaction solvent. However, the synthesized PCP is unstable to loss of guest molecules, strongly limiting its utility. In order to overcome this instability and obtain a high surface area 55 porous solid, a ligand-based solid solution approach to stabilisation was employed using a mixed ligand approach. By utilising a mixture of $2-\mathrm{NaSO}_{3}-\mathrm{H}_{2} \mathrm{BDC}$ and $\mathrm{H}_{2} \mathrm{BDC}$ as starting ligands, it is postulated that at certain intermediate compositions, the resultant mixed ligand PCP will be stable to evacuation since $60 \mathbf{1}$ is stable but $\mathbf{2}$ is not. Indeed, we succeeded in obtaining a series of frameworks, $\mathrm{Zr}_{6} \mathrm{O}_{4}(\mathrm{OH})_{4}\left(\mathrm{HSO}_{3} \mathrm{BDC}\right)_{6 x}(\mathrm{BDC})_{6-6 x} \supset \mathrm{G}$ or $\mathbf{1} / \mathbf{2}(x$ $=0.18,0.40,0.69) \supset \mathrm{G}$ where $(x=$ fraction of sulphonated ligand $)$ and observed that when $x=0.18$, the resultant PCP is stable to evacuation.

65

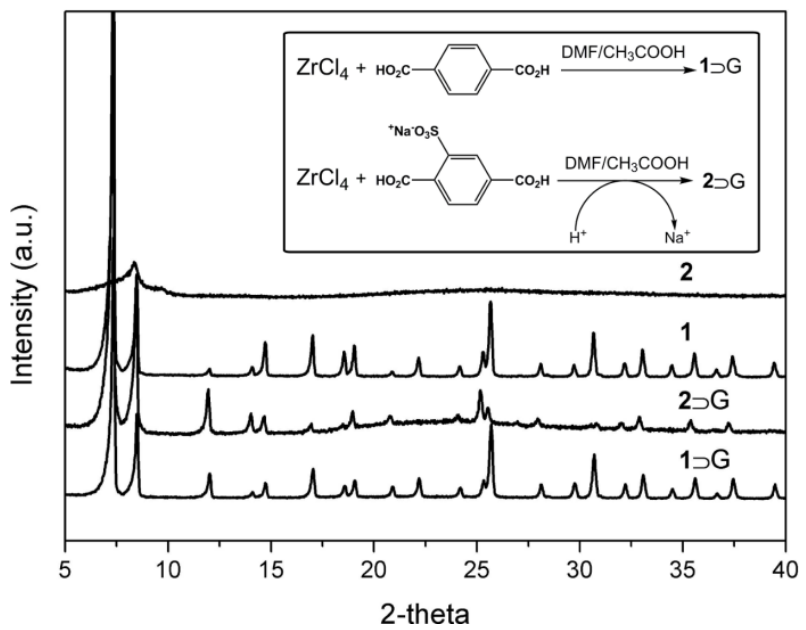

Fig. 1 Powder XRD of as-synthesized and evacuated state of $\mathbf{1}$ and $\mathbf{2}$.

$2 \supset \mathrm{G}$ was synthesized in polycrystalline form by mixing $\mathrm{ZrCl}_{4}$, $702-\mathrm{NaSO}_{3}-\mathrm{H}_{2} \mathrm{BDC}$ with a 9:1 DMF: acetic acid mixture and heating at $120{ }^{\circ} \mathrm{C}$. All attempts at formation of single crystals did not succeed. Addition of acetic acid is crucial since no crystalline product was formed without its presence. The role of acetic acid is presumably a modulator for slowing down the reaction of $\mathrm{Zr}^{4+}$ 75 with the ligand via formation of a zirconium acetate complex, similar to the revised synthesis of UiO-67, 
$\mathrm{Zr}_{6} \mathrm{O}_{4}(\mathrm{OH})_{4}(\mathrm{BPDC})_{6} \cdot{ }^{13}$ The X-ray diffraction (XRD) pattern (Fig. 1) verifies that a crystalline structure isoreticular to $1 \supset \mathrm{G}$ has been synthesized, which can be indexed to $a=20.885$ (5) $\AA$. The lattice parameter of $2 \supset \mathrm{G}$ is slightly larger than the parameters obtained 5 from $1 \supset \mathrm{G}$ synthesized under similar conditions, $a=20.786(6) \AA$. No sodium ions was detected in 2 via SEM-EDX, X-ray fluorescence and ${ }^{23} \mathrm{Na} \mathrm{NMR}$ suggesting the sulphonate oxygen may be binding to $\mathrm{Zr}$ or in-situ ion-exchange of $\mathrm{Na}^{+}$for $\mathrm{H}^{+}$has occurred. From infra-red (IR) spectroscopy, the symmetric ${ }_{10} \mathrm{O}=\mathrm{S}=\mathrm{O}\left(1080 \mathrm{~cm}^{-1}\right)$ and $\mathrm{S}=\mathrm{O}\left(1024 \mathrm{~cm}^{-1}\right)$ stretching frequencies of $\mathbf{2}$ did not vary greatly from the free ligand, suggesting that the environment of the sulphonate group is quite similar in the PCP and free ligand, i.e. no binding of the sulphonate oxygen to $\mathrm{Zr}$ has occured. However, in comparison to $\mathbf{1}$, which retains porosity of 15 evacuation, 2 was unstable to removal of guests, losing crystallinity even after evacuation at room temperature (Fig. 1). It is known that on evacuation, the SBU of UiO-66 undergoes rearrangement due to loss of $\mu^{3}-\mathrm{OH}$ with no loss of crystallinity. ${ }^{4}$ However for $2 \supset \mathrm{G}$, this same loss induces significant loss of 20 crystallinity. This is probably due to the anionic charge or protons from the sulphonate group interacting with the 12-coordinated SBU.

In order to obtain a robust framework stable to evacuation, a series of frameworks with different proportions of $\mathrm{H}_{2} \mathrm{BDC}$ and 2-

${ }_{25} \mathrm{NaSO}_{3}-\mathrm{H}_{2} \mathrm{BDC}$ ligands, $\mathbf{1 / 2}(x) \supset \mathrm{G}$ were synthesized. The initial starting stiochiometry employed was $x^{\prime}=0.25,0.50$ and 0.75 (Scheme 1) with respect to $2-\mathrm{NaSO}_{3}-\mathrm{H}_{2} \mathrm{BDC}$ ligand.

Scheme 1 Schematic for synthesis of ligand based solid solution 30 frameworks.

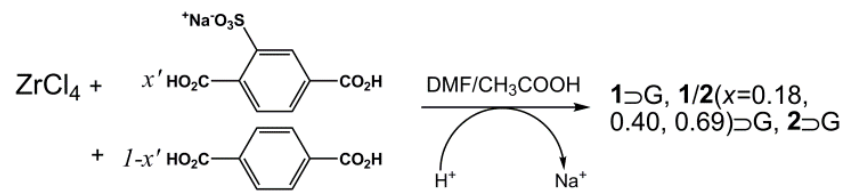

The actual composition of the frameworks was obtained by digesting the PCPs in HF (caution!)/ $/ d^{6}$-DMSO mixture, followed by performing ${ }^{1} \mathrm{H}$ NMR on the resulting solution to obtain the 35 actual composition of $x=0.18,0.40,0.69$ for the mixed ligand frameworks.

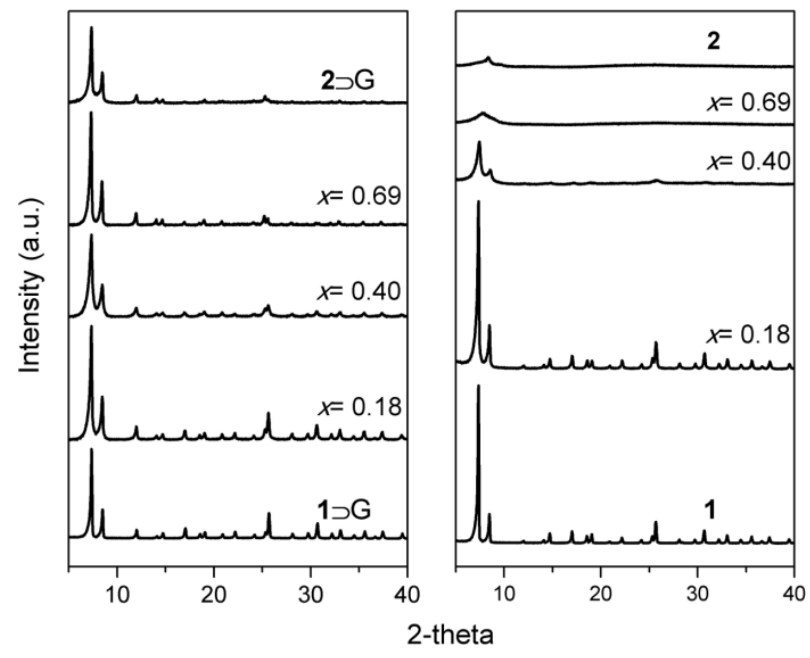

Fig. 2 (left panel) Powder XRD for as-synthesized mixed ligand 40 frameworks $\mathbf{1} \supset \mathrm{G}, \mathbf{2} \supset \mathrm{G}, \mathbf{1} / \mathbf{2}(x=0.18,0.40$ and 0.69$) \supset \mathrm{G}$. (right panel) The same frameworks after solvent exchange and evacuation at $120^{\circ} \mathrm{C}$.

Powder XRD (Fig. 2) demonstrated that the isostructure of $\mathbf{1}$ was successfully obtained using mixed ligands. The lattice parameters of the mixed ligand frameworks were obtained by 45 least square refinement of the powder X-ray data. By plotting the obtained lattice parameters against the actual composition of $x$, solid solution formation is suggested (Fig. 3). This is further supported by SEM-EDX data, verifying that the homogeneous distribution of sulphur in the mixed frameworks, indicating that 50 only one phase is present.

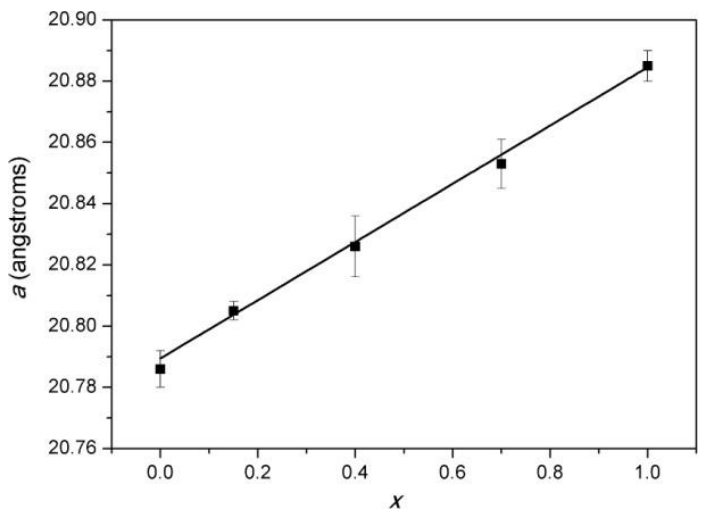

Fig. 3 Plot of lattice parameters against composition for as-synthesized frameworks, $\mathbf{1} \supset \mathrm{G}, \mathbf{2} \supset \mathrm{G}, \mathbf{1} / \mathbf{2}(x=0.18,0.40$ and 0.69$) \supset \mathrm{G}$. Note that $x=$ 550.0 is equivalent to $\mathbf{1} \supset \mathrm{G}$, and $x=1.0$ is equivalent to $2 \supset \mathrm{G}$.

After solvent exchange with acetone/water mixture and evacuation at $120{ }^{\circ} \mathrm{C}$, the crystallinity of the frameworks was determined by X-ray diffraction. It is observed that besides the $\mathbf{1}$ composition, the only other composition to stay intact was $x=$ ${ }_{60} 0.18$ (and lower $x$ ). Hence for $\mathbf{1 / 2}(x=0.18)$ or $\mathrm{Zr}_{6} \mathrm{O}_{4}(\mathrm{OH})_{4}\left(\mathrm{HSO}_{3} \mathrm{BDC}\right)_{1.1}(\mathrm{BDC})_{4.9} \supset \mathrm{G}, \quad$ a composition that incorporates the $-\mathrm{SO}_{3} \mathrm{H}$ group but is stable to evacuation at elevated temperatures is synthesized. The presence of a limiting stiochiometry is consistent with previous results on UiO-67 65 synthesized with 1,4-biphenyldicarboxylic acid and functionalized ligands. ${ }^{14}$ Le-Bail fitting of synchrotron XRD data acquired from an evacuated sample of $\mathbf{1} / \mathbf{2}(x=0.18)$ affords $a=$ 20.7382(3) $\AA$, which is larger than the previously synchrotron determined lattice parameters of $\mathbf{1} a=20.7004(2) \AA^{4}{ }^{4}$ This 70 increase in lattice parameters of the evacuated mixed ligand framework $\mathbf{1} / \mathbf{2}(x=0.18)$ compared to $\mathbf{1}$ is consistent with the results obtained from the as-synthesized samples.

The use of Hammett indicators ${ }^{15}$ on $\mathbf{1 , 2}, \mathbf{1} / \mathbf{2}(x=0.18)$ reveals that the latter two compounds possess acidic protons compared to 75 1. Upon addition of the indicator, 4-o-tolylazo-o-toluidine $\left(\mathrm{p} K_{\mathrm{a}}=\right.$ 2.0) in cyclohexanone, $\mathbf{1}$ is coloured orange (negative test) via physical adsorption of indicator, $\mathbf{1 / 2}(x=0.18)$ is dark brown (positive test) and $\mathbf{2}$ is light brown (positive test). Despite having nominally more protons, the lighter colour of $\mathbf{2}$ is due to its non80 porosity. This suggests that exchange of $\mathrm{Na}^{+}$for $\mathrm{H}^{+}$has occurred in $\mathbf{1} \mathbf{2}(x=0.18)$ as well. The exchange is further substantiated by SEM-EDX measurements showing absence of $\mathrm{Na}^{+}$for $\mathbf{1} / \mathbf{2}(x=$ $0.18)$.

Thermogravimetric Analysis (TGA) of the frameworks in 85 nitrogen shows initial weight loss ( 20\%) from room temperature 
till $200{ }^{\circ} \mathrm{C}$, which is due to solvent molecules such as acetic acid, DMF and water. From 200 to $480{ }^{\circ} \mathrm{C}$, a weight loss of $7.75 \%$ is observed for 1 but increases with increasing amounts of $x$, culminating at $19.6 \%$ for 2 . There is no drastic difference in the 5 temperature of decomposition, $\sim 500{ }^{\circ} \mathrm{C}$ for all the different frameworks.

The effect of solid solution on porosity was determined by $\mathrm{N}_{2}$ adsorption measurements and presented in Fig. 4 and Table 1. As expected, for $\mathbf{1} / \mathbf{2}(x=0.40,0.69)$ and $\mathbf{2}$, the surface area of the 10 framework decreased with increasing amounts of sulphonic acid substitution as the resulting PCP is less resistant to structural collapse upon removal of guests. However, it is surprising that for $\mathbf{1} / \mathbf{2}(x=0.18)$, the surface area is reproducibly higher than $\mathbf{1}$ with Langmuir surface area of $1436 \mathrm{vs} 1361 \mathrm{~m}^{2} \mathrm{~g}^{-1}$. Isostructural PCPs 15 synthesized from 2-substituted dicarboxylic acids as ligands usually possess lower surface areas than their unsubstituted counterparts due to steric constraints and increased molecular weight. ${ }^{5}$ There has been a recent report of using the solid solution technique to suppress interpenetration in the MOF-5 structure 20 type and the largest surface area was experimentally observed at an intermediate composition. ${ }^{16}$ However, in our case, this is not the case, as interpenetration is not possible in the UiO-66 structure type. The nominally $(\sim 5 \%)$ higher surface area observed here could be due to slightly higher crystallinity of the $\mathbf{1 / 2}(x=$ 25 0.18) framework. We note that in the literature, the Langmuir surface area of UiO-66 has increased from $1136 \mathrm{~m}^{2} / \mathrm{g}$ from its original synthesis ${ }^{4 a}$ to its current value of $1300-1400 \mathrm{~m}^{2} / \mathrm{g} .{ }^{5 \mathrm{~b}, 13}$ Therefore, the maximum obtainable Langmuir surface area for the UIO-66 structure type still remains to be optimised.

30

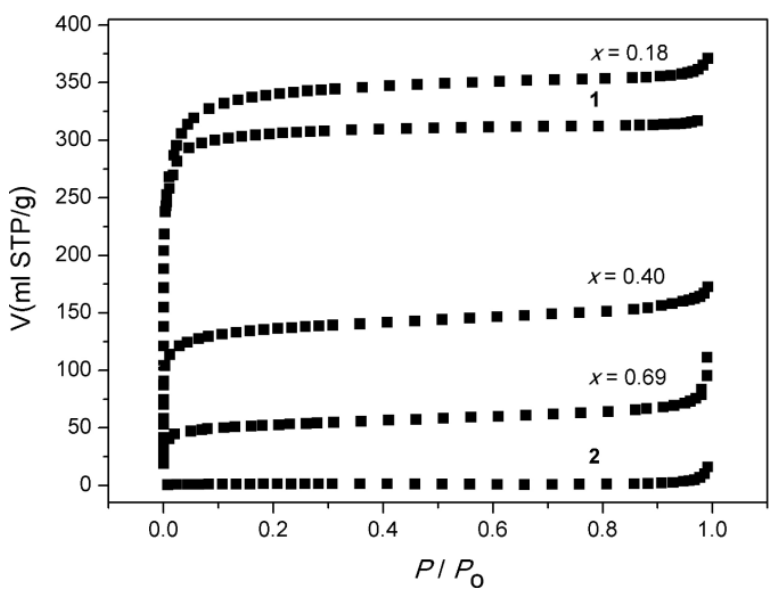

Fig. $4 \mathrm{~N}_{2}$ adsorption isotherms (77 K) for $\mathbf{1 , 2}$ and $\mathbf{1} / \mathbf{2}(x=0.18,0.40$ and $0.69)$.

In order to determine the effect of the highly polar sulphonic 35 acid group on the adsorption uptake, $\mathbf{1}$ and $\mathbf{1} / \mathbf{2}(x=0.18)$ were subjected to acetone $(298 \mathrm{~K})$ and $\mathrm{CO}_{2}$ adsorption $(288 \mathrm{~K})$ measurements (Fig. 5). The $\mathrm{CO}_{2}$ adsorption isotherm demonstrated increased uptake for $\mathbf{1} / \mathbf{2}(x=0.18)$ and it can be attributed to increased surface area and higher heats of adsorption. 40 The heat of adsorption of $\mathrm{CO}_{2}$ for $\mathbf{1} / \mathbf{2}(x=0.18)$ ranges from 28 $\mathrm{kJmol}^{-1}$ to $21 \mathrm{kJmol}^{-1}$. It is noted that heats of $30 \mathrm{kJmol}^{-1}$ has been observed for sulphonic acid functionalized porous polymer networks. ${ }^{17}$ In contrast, for $\mathbf{1}$, the heats of adsorption vary from 22 to $17 \mathrm{~kJ} \mathrm{~mol}^{-1}$. This substantial increase of $6 \mathrm{~kJ} / \mathrm{mol}$ for the ${ }_{45}$ initial heat of adsorption for $\mathbf{1} / \mathbf{2}(x=0.18)$

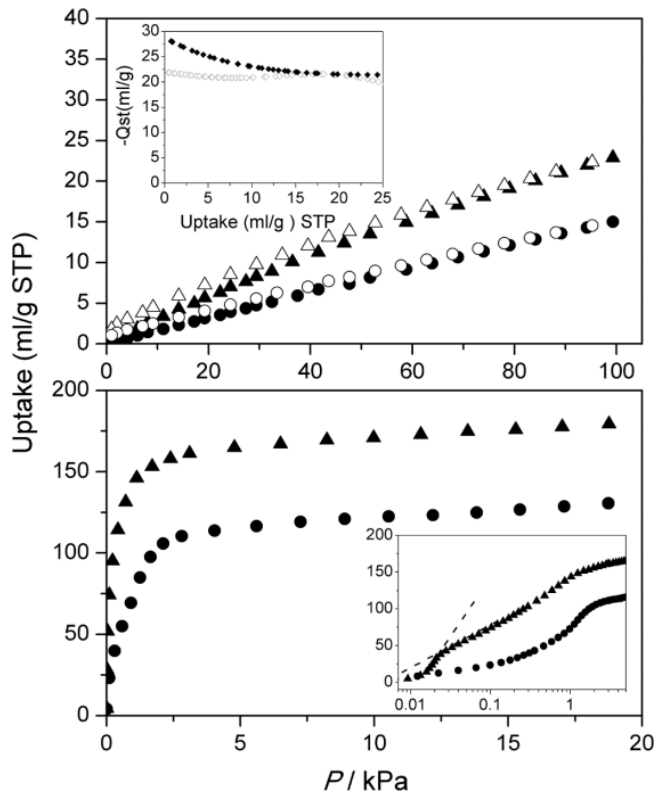

Fig. 5 (Top panel) $\mathrm{CO}_{2}$ adsorption isotherms at $288 \mathrm{~K}$ for $\mathbf{1}$ (circle) and $\mathbf{1} / \mathbf{2}(x=0.18)$ (triangle). Filled symbols represent adsorption and unfilled symbols desorption. (inset) Heats of adsorption vs uptake plot for 1(unfilled diamonds), $\mathbf{1 / 2}(x=0.18)$ (filled diamonds). (Bottom panel) 50 Acetone adsorption isotherms at $298 \mathrm{~K}$ for $\mathbf{1}$ (circles) and $\mathbf{1 / 2}(x=0.18)$ (triangles). (inset) Magnified low pressure region, showing the stepped uptake for $\mathbf{1} / \mathbf{2}(x=0.18)$.

suggests that the polar sulphonic acid substituent groups (even at relatively low $15 \%$ substitution) increases $\mathrm{CO}_{2}$ uptake and heat of 55 adsorption. The acetone sorption isotherms for both compounds also demonstrated Type I behaviour, with adsorption saturating at $P / P_{0}<0.1$. From examining the adsorption isotherms at low pressure carefully (Fig. 5 inset), it is observed that while the adsorption of acetone for $\mathbf{1}$ increases monotonically with pressure, 60 the $\mathbf{1} / \mathbf{2}(x=0.18)$ phase had a stepped increase at $P=0.0015 \mathrm{kPa}$ with an adsorption amount $\sim 20 \%$ of the total saturation uptake. This is in good correspondence with the doping level of sulphonic acid groups in the $\mathbf{1 / 2}(x=0.18)$. Interaction of the sulphonic acid group with acetone is further substantiated by infra-red (IR) 65 spectroscopy, as the $\mathrm{C}=\mathrm{O}$ stretch of acetone (neat, $\backslash 1715 \mathrm{~cm}^{-1}$ ) for $\mathbf{1} / \mathbf{2}(x=0.18) \supset$ acetone $\left(1705 \mathrm{~cm}^{-1}\right)$ is more downshifted compared to $1 \supset$ acetone $\left(1708 \mathrm{~cm}^{-1}\right)$.

In conclusion, we have synthesized and characterized sulphonic acid substituted $2 \supset \mathrm{G}$ via in-situ ion exchange of $\mathrm{Na}^{+}$ 70 for $\mathrm{H}^{+}$of the 2- $\mathrm{NaSO}_{3}-\mathrm{H}_{2} \mathrm{BDC}$ ligand during solvothermal synthesis. However, it is unstable to loss of guest molecules via evacuation, which places severe restriction on its utility. Using a ligand-based solid solution approach with $\mathrm{H}_{2} \mathrm{BDC}$ as a co-ligand, we have arrived at a composition $\mathbf{1 / 2}(x=0.18)$ with $18 \%$ 75 sulphonic acid substitution, which is robust to evacuation. The solid solution stabilisation approach suggests an alternative route to stabilise PCPs which are inherently unstable with respect to loss of guest molecules. It is thus possible to incorporate a highly acidic sulphonic acid group in UiO-66 with judicious crystal 80 design. We also show that even at relatively low levels of incorporation, the sulphonic acid group increases both the heat of adsorption and total uptake for carbon dioxide. 


\section{Notes and references}

${ }^{a}$ Japan Science and Technology Agency, ERATO, Kitagawa Integrated Pores Project, Kyoto Research Park Bldg \#3, Shimogyo-ku, Kyoto 6008815, Japan

$5{ }^{b}$ Department of Synthetic Chemistry and Biological Chemistry, Graduate School of Engineering, Kyoto University, Katsura, Nishikyo-ku, Kyoto 615-8510, Japan. Fax: +81-75-383-2732; Tel: +81-75-383-2733* Email: kitagawa@sbchem.kyoto-u.ac.jp

${ }^{c}$ Japan Science and Technology Agency, PRESTO, 4-1-8 Honcho, 10 Kawaguchi, Saitama 332-0012, Japan

${ }^{d}$ Institute for Integrated Cell-Material Sciences (WPI-iCeMS), Kyoto

University, Yoshida, Sakyo-ku, Kyoto 606-8501, Japan

${ }^{e}$ Osaka Prefecture University

${ }^{f}$ Japan Synchrotron Radiation Research Institute/SPring-8 Sayo-gun, 15 Hyogo 679-5198 (Japan)

$\dagger$ Electronic Supplementary Information (ESI) available: IR, TGA, synchrotron XRD data, colour photograph of Hammett indicator test for See DOI: 10.1039/b000000x/

20

† Synthesis of Zr frameworks

$\mathrm{Zr}_{6} \mathbf{O}_{4}(\mathbf{O H})_{4}(\mathbf{B D C})_{6} \supset \mathbf{G}$ or $1 \supset \mathbf{G}: 53 \mathrm{mg}$ of $\mathrm{ZrCl}_{4}$ (Aldrich) was added to $37.8 \mathrm{mg}$ of $\mathrm{H}_{2} \mathrm{BDC}$ (TCI) in a $20 \mathrm{ml}$ glass vial. $9 \mathrm{ml}$ of DMF (Wako) and $251 \mathrm{ml}$ of acetic acid (Wako) was then added. The vial was sealed with a Teflon cap and heated for $40 \mathrm{hrs}$ at $120^{\circ} \mathrm{C}$. The product was then centrifuged (2,000 rpm for $15 \mathrm{~min})$ and washed with DMF. This process was repeated for three times. The mixture was then washed with diethylether, followed by air-drying. Weight of product $=50 \mathrm{mg}$.

$\mathrm{Zr}_{6} \mathrm{O}_{4}(\mathrm{OH})_{4}\left(\mathbf{H S O}_{3} \mathbf{B D C}\right)_{6} \supset \mathbf{G}$ or $2 \supset \mathbf{G}: 53 \mathrm{mg}$ of $\mathrm{ZrCl}_{4}$ (Aldrich) was added to $61 \mathrm{mg}$ of $2-\mathrm{NaSO}_{3}-\mathrm{H}_{2} \mathrm{BDC}$ (TCI) in a $20 \mathrm{ml}$ glass vial. $9 \mathrm{ml}$ of DMF (Wako) and $1 \mathrm{ml}$ of acetic acid (Wako) was then added. The vial was sealed with a Teflon cap and heated for $40 \mathrm{hrs}$ at $120^{\circ} \mathrm{C}$. The product 35 was then suction filtered and washed with DMF and diethylether, followed by air-drying. Weight of product $=61 \mathrm{mg}$.

$\mathrm{Zr}_{6} \mathrm{O}_{4}(\mathrm{OH})_{4}\left(\mathrm{HSO}_{3} \mathbf{B D C}\right)_{6-6 \mathrm{rr}}(\mathrm{BDC})_{6} \supset \mathbf{G}$ or $\mathbf{1 / 2}(x)_{\supset} \mathbf{G}$ : To obtain the PCPs with mixed ligands, the procedure followed is the same as the 40 synthesis of 2, except for addition of nominal stoichiometric amounts of $\mathrm{H}_{2} \mathrm{BDC}$ and $2-\mathrm{NaSO}_{3}-\mathrm{H}_{2} \mathrm{BDC}$ for $x^{\prime}=0.25,0.500 .75$ For example when $x^{\prime}=0.25,25.5 \mathrm{mg}$ of $\mathrm{H}_{2} \mathrm{BDC}$ and $15.25 \mathrm{mg}$ of $2-\mathrm{NaSO}_{3}-\mathrm{H}_{2} \mathrm{BDC}$ were used.

1 (a) S. Kitagawa, R. Kitaura and S. Noro, Angew. Chem. Int. Ed., 45 2004, 43, 2334-2375; (b) J. L. C. Rowsell and O. M. Yaghi, Microporous Mesoporous Mater., 2004, 73, 3-14; (c) G. Férey, C. Mellot-Dranznieks, C. Serre and F. Millange, Acc. Chem. Res., 2005, 38, 217; (d) S. Batten and R. Robson, Angew. Chem., Int. Ed., 1998, 37, 1460; (e) H.-C. Zhou, J. R. Long, O. M. Yaghi, Chem. Rev. 2012, so $\quad 112,673-674$ (feature issue)

2 (a) R. J. Kuppler, D. J. Timmons, Q. R. Fang, J. R. Li, T. A. Makal, M. D. Young, D. Q. Yuan, D. Zhao, W. J. Zhuang and H. C. Zhou, Coord. Chem. Rev., 2009, 253, 3042-3066; (b) L. Q. Ma, C. Abney and W. B. Lin, Chem. Soc. Rev., 2009, 38, 1248-1256; (c) A. C.

55 McKinlay, R. E. Morris, P. Horcajada, G. Ferey, R. Gref, P. Couvreur and C. Serre, Angew. Chem. Int. Ed., 49, 6260-6266.

3 J. J. Low, A. I. Benin, P. Jakubczak, J. F. Abrahamian, S. A. Faheem and R. R. Willis, J. Am. Chem. Soc., 2009, 131, 15834-15842.

4 (a) J. H. Cavka, S. Jakobsen, U. Olsbye, N. Guillou, C. Lamberti, S. 60 Bordiga and K. P. Lillerud, J. Am. Chem. Soc., 2008, 130, 1385013851; (b) L. Valenzano, B. Civalleri, S. Chavan, S. Bordiga, M. H. Nilsen, S. Jakobsen, K. P. Lillerud and C. Lamberti, Chem. Mat., 2011, 23, 1700-1718; (c) M. Kim and S. M. Cohen, CrystEngComm., 2012, 14, 4096-4104(review).

${ }_{65} 5$ (a) M. Kandiah, M. H. Nilsen, S. Usseglio, S. Jakobsen, U. Olsbye, M. Tilset, C. Larabi, E. A. Quadrelli, F. Bonino and K. P. Lillerud, Chem. Mat., 2010, 22, 6632-6640; (b) S. J. Garibay and S. M. Cohen, Chem. Comm., 2010, 46, 7700-7702.

6 (a) K. A. Mauritz and R. B. Moore, Chem. Rev., 2004, 104, 4535-

70 4586; (b) G. Gelbard, Ind. Eng. Chem. Res., 2005, 44, 8468-8498.
7 D. Britt, C. Lee, F. J. Uribe-Romo, H. Furukawa and O. M. Yaghi, Inorg. Chem., 2010, 49, 6387-6389.

8 G. Akiyama, R. Matsuda, H. Sato, M. Takata and S. Kitagawa, $A d v$. Mat., 2011, 23, 3294-3297.

759 M. G. Goesten, J. Juan-Alcañiz, E. V. Ramos-Fernandez, K. B. Sai Sankar Gupta, E. Stavitski, H. van Bekkum, J. Gascon and F. Kapteijn, J. Catal., 2011, 281, 177-187.

10 (a) A. D. Burrows, CrystEngComm., 2011, 13, 3623-3642; (b) T. Fukushima, S. Horike, Y. Inubushi, K. Nakagawa, Y. Kubota, M.

80 Takata and S. Kitagawa, Angew. Chem. Int. Ed., 2010, 49, 46874687; (c) S. Horike, Y. Inubushi, T. Hori, T. Fukushima and S. Kitagawa, Chem. Sci, 2012, 3, 116-120.

11 (a) H. Chun, D. N. Dybtsev, H. Kim and K. Kim, Chem. Eur. J., 2005, 11, 3521-3529; (b) K. Koh, A. G. Wong-Foy and A. J. Matzger,

85 Chem. Comm., 2009, 6162-6164; (c) S. Marx, W. Kleist, J. Huang, M Maciejewski and A. Baiker, Dalton Trans., 2010, 39, 3795-3798.

12 H. Deng, C. J. Doonan, H. Furukawa, R. B. Ferreira, J. Towne, C. B. Knobler, B. Wang and O. M. Yaghi, Science, 2010, 327, 846-850.

13 A. Schaate, P. Roy, A. Godt, J. Lippke, F. Waltz, M. Wiebcke and P. 90 Behrens, Chem.Eur. J., 2011, 17, 6643-6651.

14 C. Wang, Z. Xie, K. E. deKrafft and W. Lin, J. Am. Chem. Soc., 2011, 133, 13445-13454.

15 B. Coughlan and M. A. Keane, J. Colloid Interf. Sci. 1990, 137, 483494.

9516 T.-H. Park, K. Koh, A. G. Wong-Foy and A. J. Matzger, Cryst. Growth Des., 2011, 11, 2059-2063.

17 W. Lu, D. Yuan, J. Sculley, D. Zhao, R. Krishna and H.-C. Zhou, J. Am. Chem. Soc., 2011, 133, 18126-18129. 


\section{Table of contents}

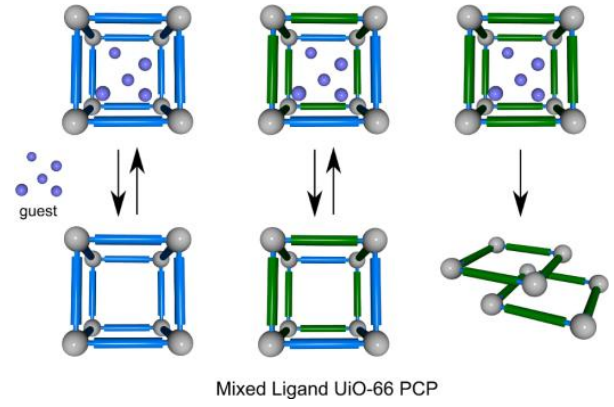

